\title{
OFICINAS DE CÁLCULO MENTAL E CALCULADORA: PESQUISA E PRÁTICA NA FORMAÇÃO DE PROFES- SORES DE MATEMÁTICA NO CURSO DE LICENCIATURA EM EDUCAÇÃO DO CAMPO DA UFMG
}

\section{WORKSHOPS OF MENTAL CALCULATION AND CALCULATOR: RESEARCH AND PRACTICE IN THE TRAINING OF MATHEMATICS TEACHERS IN THE COURSE OF LICENCIATURE IN EDUCATION OF THE FIELD OF UFMG}

Laís Macedo de Almeida Nunes ${ }^{1}$, Nayara Katherine Duarte Pinto², Flávia Cristina Duarte Pôssas Grossi ${ }^{3}$, Keli Cristina Conti ${ }^{4}$

\section{RESUMO}

Este artigo busca apresentar aspectos teóricos significativos do cálculo mental e da calculadora, bem como discorrer sobre as vantagens de se desenvolver um trabalho com essas duas competências de cálculo em sala de aula. O foco do trabalho é apresentar considerações sobre a formação de professores de Matemática a partir de duas oficinas sobre a calculadora e o cálculo mental realizadas no Laboratório de Ensino de Matemática da Faculdade de Educação da Universidade Federal de Minas Gerais. As oficinas tiveram como público-alvo estudantes do curso de Licenciatura em Educação no Campo - Habilitação Matemática - e objetivaram proporcionar momentos de reflexões e práticas sobre o cálculo mental e a calculadora na sala de aula, de maneira a estimular esses futuros professores a utilizarem essas duas modalidades de cálculo em suas turmas da Educação Básica. Os dados que subsidiaram a análise foram produzidos a partir de registros em áudio, registros fotográficos e questionários aplicados aos licenciandos. Após um retorno positivo dos participantes das oficinas, concluímos e salientamos a relevância dessas temáticas terem sido trabalhadas na oficina de maneira a complementar a formação inicial dos futuros professores de Matemática.

PALAVRAS-CHAVE: Calculadora. Cálculo Mental. Educação do Campo. Educação Matemática. Formação de professores de Matemática.

\section{ABSTRACT}

This article seeks to present significant theoretical aspects of mental calculation and calculator, as well as talk about the advantages of developing a work with this two-calculation competence in the classroom. The focus of the paper is to present considerations about the formation of Mathematics teachers from two workshops on the calculator and mental calculation carried out in the Mathematics Teaching Laboratory of the Faculty of Education of the Federal University of Minas Gerais. The workshops were aimed at students of the Undergraduate Education in the Field Mathematical Habilitation- course and aimed to provide moments of reflection and practice about mental calculus and calculator in the classroom in order to encourage these future teachers to use these two modalities of calculation in their classes of Basic Education. The data that subsidized the analysis were produced from audio records, photographic records and questionnaires applied to undergraduatings. After a positive feedback from the workshop participants, we conclude and emphasize the relevance of these themes being worked on in the workshop to complement the initial training of future Mathematics teachers.

KEYWORDS: Calculators. Mental Calculation. Field Education. Mathematics Education. Teacher training in Mathematics.

\footnotetext{
${ }_{1}^{1}$ Mestranda no Programa de Mestrado Profissional em Rede Nacional (PROFMAT - CEFET).

2 Mestranda em Educação e Docência no programa de mestrado profissional da Faculdade de Educação da Universidade Federal de Minas Gerais (Promestre/FaE/UFMG).

${ }^{3}$ Doutoranda em Educação no Programa de Pós-graduação Conhecimento e Inclusão Social da Faculdade de Educação da Universidade Federal de Minas Gerais (FaE/UFMG).

${ }^{4}$ Doutorado em Educação pela Universidade Estadual de Campinas. Professora Adjunta da Faculdade de Educação da Universidade Federal de Minas Gerais (FaE/UFMG).
} 


\section{INTRODUÇÃO}

Esta pesquisa integra um projeto intitulado "Contribuições do Laboratório de Ensino de Matemática para a formação inicial do professor que ensina Matemática", que visou ampliar o Laboratório de Ensino de Matemática (LEM) da Faculdade de Educação da Universidade Federal de Minas Gerais (FaE/UFMG). O projeto buscou analisar e interpretar práticas de formação e de atuação de futuros professores de forma a compreender e ressaltar a importância de um LEM para a formação inicial do professor que ensinará Matemática, seja no campo ou na cidade, e seu reflexo no processo de ensino e aprendizagem dos estudantes. Visou, também, a criação de um ambiente que pudesse dar suporte ao planejamento de atividades de estágio e à realização da prática pedagógica das disciplinas do núcleo pedagógico dos diversos cursos oferecidos pela Faculdade de Educação da UFMG, sendo eles: o curso de Licenciatura em Matemática; o curso de Licenciatura em Educação do Campo (nosso destaque neste artigo); os cursos de Pedagogia (presencial e a distância); e o curso de Licenciatura em Formação Intercultural para Educadores Indígenas. Todos esses cursos envolvem a formação de futuros professores que irão ensinar Matemática, levando em consideração os objetivos de cada curso e as especificidades de cada tipo de formação. Nesse contexto, partindo da indissociabilidade entre teoria e prática, surgiram estudos e oficinas que serão abordados neste trabalho.

A presente produção tem como objetivo, portanto, apresentar aspectos teóricos significativos sobre cálculo mental e calculadora, bem como discorrer sobre as vantagens de se desenvolver um trabalho com essas duas competências de cálculo em sala de aula. Outro propósito dessa produção é apresentar considerações a partir de duas oficinas realizadas com os estudantes do curso de Licenciatura em Educação do Campo - Habilitação Matemática - com o objetivo de proporcionar reflexões e atividades práticas em relação a essas duas temáticas e de estimulá-los a promoverem um trabalho com essas duas modalidades de cálculo no ambiente escolar.

\section{ASPECTOS TEÓRICOS}

De acordo com a Base Nacional Comum Curricular (BNCC), "no tocante aos cálculos, espera-se que os alunos desenvolvam diferentes estratégias para a obtenção dos resultados, sobretudo por estimativa e cálculo mental, além de algoritmos e uso de calculadoras" (BRASIL, 2018, p. 268). Nesse sentido, Lopes e Rodriguez (2009) enfatizam que, para o desenvolvimento de competências de cálculo, é importante um equilíbrio entre as quatro competências de cálculo, uma vez que "os diferentes procedimentos e tipos de cálculo relacionam-se e complementam-se" (BRASIL, 1997, p.75).

Lopes e Rodriguez (2009), apresentam a ilustração de uma mesa (Figura 1) para reforçar a importância do equilíbrio entre as competências. Cada "pé da mesa" representa uma competência.

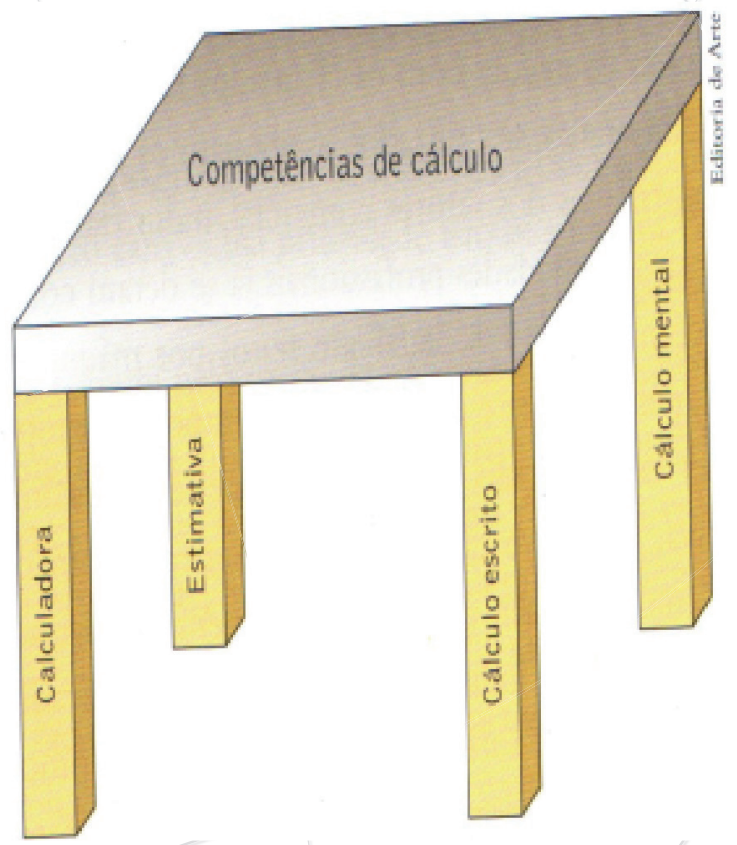

Figura 1: Competências de cálculo.

Figure 1: Calculation competences.

Fonte: Lopes; Rodriguez; 2009, p. 147.

No que diz respeito às competências de cálculo, de acordo com a BNCC, "é necessário acrescentar, à realização dos algoritmos das operações, a habilidade de efetuar cálculos mentalmente, fazer estimativas, usar calculadora e, ainda, para decidir quando é apropriado usar um ou outro procedimento de cálculo" (BRASIL, 2018, p. 276).

Diferentes propostas de educação matemática têm visado ao uso de novas tecnologias e calculadoras na sala de aula, demonstrando as contribuições des- 
sas ferramentas nos processos de ensino e aprendizagem, e, em meio a essas propostas, surge, também, a necessidade da valorização do cálculo mental e da estimativa, uma vez que o cálculo escrito já é bem explorado em sala de aula. Gomes (2007) afirma que o cálculo mental tem sido valorizado por sua utilidade e por suas vantagens, mas, principalmente, por seu valor cognitivo, já que a sua utilização desenvolve a qualidade de raciocínio lógico e matemático. A referida autora ainda afirma, mediante pesquisa, que "contas de cabeça, exatas ou aproximadas junto à calculadora são os recursos mais utilizados pelos brasileiros em situações cotidianas" (GOMES, 2007, p. 13).

Essas duas competências de cálculo têm sido alvo de estudos de diferentes pesquisadores, que têm como objetivo destacar as diferentes utilidades e abordagens que um trabalho contínuo com o cálculo mental e com a calculadora pode trazer a um estudante. Sendo essas duas temáticas ainda pouco exploradas na sala de aula, torna-se necessário formar professores para a Educação Básica que, em sua experiência docente, estimulem os estudantes a exercerem tal prática. Tendo isso em vista, foram, então, ministradas duas oficinas, uma de cálculo mental e outra de calculadora, para estudantes da habilitação em Matemática do curso de Licenciatura em Educação do Campo (LECampo) da Universidade Federal de Minas Gerais.

\section{CÁLCULO MENTAL}

Para alguns autores, "cálculo mental" está relacionado à rapidez com que se faz uma conta ou à memorização. Para outros, cálculo mental é o oposto do cálculo escrito, sendo considerado qualquer cálculo que possa ser feito sem "lápis e papel" ou sem o auxílio de qualquer outro instrumento a não ser a mente. Parra (1996) afirma que a expressão pode apresentar diferentes significados, podendo ser entendida de diferentes formas.

De maneira geral, o cálculo mental é compreendido como aquele tipo de cálculo desenvolvido, preferencialmente, com a "cabeça". De acordo com as definições dadas por Parra (1996) e Bourdenet (2007), existem dois tipos de cálculo mental: o primeiro é o cálculo pensado ou refletido - utiliza estratégias para ser efetuado - e o segundo é o cálculo automático ou decorado - efetua a conta armada mentalmente utili- zando os algoritmos das operações.

A prática contínua do cálculo mental, principalmente com o uso do cálculo pensado, possui vantagens consideráveis e muito úteis. De acordo com Imenes, em entrevista à Ribeiro (2005), a maior vantagem do cálculo mental não é fazer as contas rapidamente, porque, atualmente, é desnecessário desejar competir com a calculadora. No entanto, considerando o ambiente escolar, em que nem sempre é permitido o uso das calculadoras, o cálculo mental pode ser uma boa alternativa para os estudantes, já que, muitas vezes, pode ser efetuado de maneira mais ágil e rápida do que o algoritmo tradicional escrito.

O cálculo mental é fundamentado nas propriedades das operações matemáticas e do sistema decimal de numeração, dessa forma, o estudante que utiliza essa modalidade de cálculo desenvolve diferentes técnicas operatórias, levando-o a compreender melhor o sistema de numeração. Parra (1996) afirma que a utilização do cálculo mental aumenta o conhecimento no campo numérico daqueles que o utilizam. Os Parâmetros Curriculares Nacionais corroboram a ideia ao afirmarem:

No cálculo mental, a reflexão centra-se no significado dos cálculos intermediários e isso facilita a compreensão das regras do cálculo escrito. $\mathrm{O}$ exercício e a sistematização dos procedimentos de cálculo mental, ao longo do tempo, levam-no a ser utilizado como estratégia de controle do cálculo escrito (BRASIL, 1997, p. 76).

Sendo a mente o principal "instrumento" do cálculo mental, este estimula a memória e desenvolve a qualidade do raciocínio, tanto matemático quanto lógico. Brocardo (2011) aponta que "quando se tem sentido de número e, consequentemente, desenvolvido um bom cálculo mental, consegue-se olhar para situações com que nos deparamos de um modo interrogativo" (BROCARDO, 2011, p. 9). Podemos afirmar, então, que, de certa maneira, essa modalidade de cálculo aperfeiçoa o senso crítico matemático e pessoal, concordando com Araújo e Soares, os quais afirmam que "uma atenção privilegiada ao cálculo mental na escola incentiva os alunos a desenvolverem suas próprias maneiras de enfrentar os desafios que Ihes são pro- 
postos" (ARAÚJO; SOARES; 2002 p. 35).

Butlen e Pezard (2000, apud GONÇALVES e FREITAS, 2008) $)^{5}$ alegam que a prática com o cálculo mental "libera espaço mental" para a resolução de problemas, afirmando que a utilização contínua dessa modalidade de cálculo aumenta a capacidade de iniciativa do aluno, levando-o a explorar diferentes formas de resolver um único problema ou operação. Além disso, estimativas e aproximações são processos e estratégias utilizadas no uso do cálculo mental, concedendo ao estudante a habilidade de antecipar e avaliar, aproximadamente, os resultados de um problema.

Ao conhecer as diferentes vantagens que essa prática pode proporcionar, é importante que os estudantes sejam incentivados a utilizarem essa modalidade de cálculo na Educação Básica. Gonçalves e Freitas (2008) alertam que o cálculo mental é, ocasionalmente, trabalhado na sala de aula e que muitas atividades com o cálculo mental são apresentadas apenas durante o Ensino Fundamental I, junto ao ensino do algoritmo comum.

Bigode, entrevistado por Gentile (2018), disse que o cálculo mental deve ser frequentemente realizado e incentivado nas salas de aula, sendo considerados, dessa forma, um objetivo pedagógico a ser alcançado. Brocardo (2011) corrobora a ideia acima, afirmando que "desenvolver o cálculo mental é uma tarefa continuada, a ser levada a cabo em todos os níveis de ensino e de forma sistemática" (BROCARDO, 2011 , p. 10). De acordo com a referida autora, o professor tem um papel fundamental no sentido de desenvolver o cálculo mental dos alunos e deve ser capaz de propor tarefas que agucem o interesse e os estimulem a utilizar essa modalidade de cálculo.

\section{CALCULADORAS}

O uso da calculadora está presente na nossa rotina (por exemplo, quando usamos as calculadoras de bolso, dos celulares e dos computadores), mas ainda é pouco utilizada na sala de aula. Atualmente, muitos professores e pais ainda veem o uso da calculadora na escola como algo errado e com o preconceito de

${ }^{5}$ BUTLEN, D.; PEZARD, M. et al., Calcul mental et resolution de problèmes numèriques au début du college, Repères-IREM, n. 41, p.5-24, Metz: Topiques Editions, Metz, 2000 que esse uso prejudicaria o desenvolvimento dos estudantes na aprendizagem das operações básicas ou os tornaria "preguiçosos".

O uso da calculadora tem sido recomendado pelos Parâmetros Curriculares Nacionais (PCNs) em várias situações, assim como o uso de computadores e outros instrumentos tecnológicos, destacando que os estudantes devem "conviver com outras modalidades de cálculo, como o cálculo mental, as estimativas e o cálculo produzido pelas calculadoras, portanto, não se pode privar as pessoas de um conhecimento que é útil em suas vidas" (BRASIL, 1998, p. 45).

O documento reforça e defende o uso da calculadora como um recurso que traria contribuições para o ensino da Matemática:

Quanto ao uso da calculadora, constata-se que ela é um recurso útil para verificação de resultados, correção de erros, podendo ser um valioso instrumento de auto-avaliação. A calculadora favorece a busca e percepção de regularidades matemáticas e o desenvolvimento de estratégias de resolução de situações-problema pois ela estimula a descoberta de estratégias e a investigação de hipóteses, uma vez que os alunos ganham tempo na execução dos cálculos. Assim elas podem ser utilizadas como eficiente recurso para promover a aprendizagem de processos cognitivos (BRASIL, 1998, p. 45).

Ainda nesse sentido, Van de Walle (2009) destaca alguns mitos e medos, em grande parte, baseados na pouca informação a respeito:

a) Se as crianças usarem calculadoras, elas não aprenderão os "fundamentos";

b) As calculadoras tornam os estudantes preguiçosos;

c) Os estudantes devem aprender o "modo real" antes de usar calculadoras;

d) Os estudantes se tornarão dependentes demais de calculadoras (WALLE, 2009, p. 131-132).

Concordamos com Van de Walle (2009, p. 130), quando ele afirma: "em vez de temer o dano potencial 
que as calculadoras podem causar, é importante compreender como as calculadoras podem contribuir para a aprendizagem da Matemática". Consideramos que o uso correto da calculadora pode subsidiar o desenvolvimento dos estudantes com as operações e com o raciocínio lógico, bem como desenvolver conceitos e fortalecer a resolução de problemas, porque esse instrumento ajuda os estudantes a economizarem o tempo ao ser utilizado nas práticas sociais (VAN DE WALLE, 2009).

O ser humano é responsável por manipular a calculadora até que ela encontre o resultado correto para uma determinada operação ou situação-problema, por isso é necessário o desenvolvimento de um raciocínio antecipado para que a atividade se torne "mais rica, sem riscos de impedir o desenvolvimento do pensamento, desde que os alunos sejam encorajados a desenvolver seus processos metacognitivos e sua capacidade crítica" (BRASIL, 1998, p. 45). Isso é destacado por Van de Walle (2009, p. 132), ao declarar que, "quando usadas adequadamente, as calculadoras aumentam a aprendizagem; elas não atrapalham o caminho da aprendizagem".

De acordo com Lopes e Rodriguez (2009, p. 147), boas propostas com o uso das calculadoras potencializam "a capacidade dos alunos de fazer, mais e melhor, cálculo mental e estimativa, bem como ajudam a compreender o que fazem (às vezes mecanicamente) no cálculo escrito".

Lopes e Rodriguez (2009, p. 148) apresentam que, devido ao valor de cada calculadora, ela não deve ser usada na escola. No entanto, atualmente, essa justificativa não procede, porque é possível adquirir uma calculadora simples "pelo preço de uma passagem de ônibus municipal".

Selva e Borba (2010) defendem que nem sempre o uso da calculadora proporciona explorações conceituais. As autoras ressaltam que para alcançar esse objetivo, são necessárias situações didáticas bem planejadas, com procedimentos bem selecionados. Como a calculadora não opera por si mesma, é preciso criar ambientes nos quais os estudantes decidirão os procedimentos a serem tomados para resolverem determinados problemas.

\section{METODOLOGIA}

As oficinas foram realizadas com estudantes do curso de Licenciatura em Educação do Campo - Habilitação Matemática -, uma vez que esses estudantes, como futuros professores, podem ser estimulados e preparados para incentivar o uso do cálculo mental e das calculadoras na sala de aula.

Nesse sentido, a pesquisa se dividiu em três fases. A primeira fase foi a realização de uma pesquisa bibliográfica ou estudo documental, de acordo com Fiorentini e Lorenzato (2006), em que foram feitos levantamentos de livros, publicações, artigos e dissertações que tratavam das temáticas sobre o cálculo mental e a calculadora, a fim de, inicialmente, aprofundar-se sobre o assunto.

Após as leituras, na segunda fase, foram elaboradas duas oficinas, uma sobre cálculo mental e outra sobre o uso da calculadora. As oficinas tiveram a intenção de refletir sobre e discutir a importância e as vantagens da utilização do cálculo mental e da calculadora de maneira a incentivar esses futuros professores de Matemática a usufruírem dessas duas competências de cálculos em suas práticas docentes na sala de aula. Nessa fase, usamos questionários on-line e impressos como instrumentos de coleta de informações, além dos registros de áudio das interações entre os/as estudantes, as bolsistas e a professora, e registros fotográficos. Em cada encontro para a realização das oficinas, os futuros professores responderam de maneira anônima um questionário inicial sobre as perspectivas preliminares sobre o assunto alvo das oficinas e um questionário final sobre as novas perspectivas acerca do assunto trabalhado, além de avaliar a proposta e se autoavaliar.

A terceira fase da pesquisa foi desenvolvida numa abordagem qualitativa (BOGDAN; BIKLEN, 1994). Optamos por essa abordagem a fim de analisar e valorizar todos os dados qualitativos (descrição detalhada das situações, contextos, sujeitos, interações, comportamentos, falas dos futuros professores, atitudes, concepções, pensamentos, entre outros) como importantes para assegurar o compromisso com a produção de conhecimento.

Com relação ao curso de origem dos estudantes que participaram das oficinas, é importante salientar 
que a Licenciatura em Educação do Campo (LECampo) é um curso específico, voltado aos interesses da vida no campo, fundamentado em formar professoras e professores que irão atuar nas escolas do campo, atentos às demandas do universo campesino. Um dos objetivos do curso é desenvolver, "a partir da especificidade das questões da Educação do Campo, um projeto de formação que articule os saberes da experiência com os saberes produzidos nas diferentes áreas do conhecimento científico" (UFMG, 2009, p. 1), e assim, "preparando educadores para uma atuação profissional que vá além da docência e dê conta da gestão dos processos educativos que acontecem na escola do campo e no seu entorno" (UFMG, 2009, p. 1).

A LECampo UFMG propõe e organiza o seu currículo em torno de quatro áreas de conhecimento (Língua, Arte e Literatura; Ciências da Vida e da Natureza; Ciências Sociais e Humanidades e Matemática), com espaços e tempos de formação que acontecem em regime de alternância ${ }^{6}$. No trabalho de Auarek e Viseu (2017), eles detalham essa organização do curso:

Ao propor a Alternância como referencial pedagógico, o LECampo assume uma estrutura de funcionamento própria e distinta dos demais cursos oferecidos na UFMG, pois a metodologia de alternância desenvolvida organiza-se de maneira tal que o licenciando alterne as suas atividades entre: 1) o Tempo Escola (TE) - tempo de formação na Faculdade de Educação - UFMG; e 2) o Tempo Comunidade - tempo para refletir e planejar atividades pedagógicas a partir da prática social junto da comunidade rural em consonância com os conhecimentos e teorias, relativos à área de formação, estudados no Tempo Escola (TE) (AUAREK; VISEU, 2017, p.5).

As oficinas aconteceram durante o Tempo Escola, no primeiro semestre de 2019 do curso de Li-

\footnotetext{
6 "A Pedagogia de Alternância prevê uma oportunidade formativa ao considerar espaços educacionais formais e não formais, possibilitando pensar outros formatos para o processo formativo do professor do Campo. Ela potencializa a aproximação entre a Universidade e os processos de produção de conhecimento dos sujeitos do campo, fortalecendo os modos de vida campesinos" (MOLINA, 2015).
}

cenciatura em Educação do Campo, habilitação em Matemática, momento em que os futuros professores estavam no $6^{\circ}$ semestre do curso. Os licenciandos estavam cursando a disciplina Análise da Prática Pedagógica VI. Essa disciplina teve como objetivo orientar o estágio supervisionado e possibilitar discussões acerca da prática pedagógica, instrumentalizando os licenciandos em perspectivas teóricas e práticas (indissociáveis). Por isso, a nossa opção em executar as oficinas nessa disciplina.

A oficina de cálculo mental aconteceu no dia 06 e a de calculadora no dia 07 do mês fevereiro deste ano. As oficinas contaram com a participação de 18 futuros professores, estudantes do curso de Licenciatura em Educação do Campo (LECampo), habilitação em Matemática. Elas ocorreram no Laboratório de Ensino de Matemática (LEM) da Faculdade de Educação (FaE) da UFMG.

\section{CONTEXTO PRÁTICO}

\section{OFICINA DE CÁLCULO MENTAL}

A oficina de cálculo mental iniciou com uma discussão e reflexão acerca das respostas dadas pelos futuros professores no questionário inicial, a partir das quais foram apresentados alguns aspectos teóricos sobre o tema. Quando foram questionados sobre se sentirem seguros ao realizarem uma conta mentalmente, a maioria dos licenciandos disse que depende da complexidade da operação que será calculada, se sentido seguros apenas quando os cálculos são mais simples e usam as quatro operações básicas (soma, subtração, multiplicação e divisão). Um futuro professor disse que não se sente "muito seguro", porque está acostumado a fazer os cálculos "no papel", devido às práticas escolares. Essa resposta ilustra uma situação de desequilíbrio na mesa proposta por Lopez e Rodrigues (2009), porque o cálculo escrito e os algoritmos são as modalidades mais favorecidas.

Ainda sobre a segurança dos futuros professores para trabalhar com o cálculo mental na sala de aula, eles responderam: "Não, pois raramente faço isso. Então não me familiarizei"; "Sim, pois eu sempre estou realizando esses cálculos". As respostas selecionadas nos instigam a refletir sobre a importância da prática e de um trabalho contínuo em relação ao cál- 
culo mental. Citamos dois extremos, o futuro professor que tem facilidade pois sempre treina esses cálculos, e o futuro professor que não possui tal habilidade, porque raramente treina essa modalidade no momento de resolver as operações.

Sobre a definição de cálculo mental, $78 \%$ dos futuros professores indicaram a mente como a ferramenta necessária nessa modalidade. Todos citaram que o cálculo deve ser feito "de cabeça", ou seja, de maneira mental. Três futuros professores associaram essa modalidade de cálculo à rapidez e à agilidade em que as operações são solucionadas. Boa parte dos futuros professores disse que utilizam o cálculo mental em situações cotidianas, como no comércio e na manipulação de dinheiro.

Em resposta à questão: "Você se lembra de ter estudado e/ou utilizado o cálculo mental em algum ano da Educação Básica? Se sim, quais anos?", ao contrário do esperado, boa parte dos futuros professores se lembrou de ter utilizado o cálculo mental em diferentes anos da Educação Básica e não apenas nos Anos Iniciais do Ensino Fundamental junto ao ensino dos algoritmos, como foi destacado por Gonçalves e Freitas (2008). As respostas obtidas para essa questão foram: "Não. Não. Não. Sempre foram algoritmos"; "Usávamos o cálculo mental por falta de acesso aos meios tecnológicos práticos e rápidos dos dias atuais"; "Estudado não, mas já utilizei"; "Não, nos Anos Iniciais do Ensino Fundamental eu não me lembro. Mas a partir daí sim, tanto no Ensino Fundamental II e Ensino Médio, porém, isso não acontecia no ambiente escolar"; "Sim, nos Anos Iniciais quando realizávamos as quatro operações". Essas respostas indicam a importância de refletirmos sobre essa modalidade de cálculo ser abordada e usada na sala de aula, de maneira que os professores incentivem os estudantes a praticarem e a utilizarem o cálculo mental, estimulando os estudantes a criarem suas próprias estratégias mentais ao solucionarem as operações.

Quando questionados em relação à utilidade do cálculo mental em meio às novas tecnologias, apenas um futuro professor considerou desnecessário o trabalho e o ensino dessa modalidade de cálculo. Um licenciando afirmou: "Acho muito útil porque acredito na tecnologia como uma ferramenta de complementação e não de substituição".
Para finalizar o questionário inicial, foi perguntado se eles, estando como professores na sala de aula incentivariam a prática do cálculo mental aos seus alunos. Somente três futuros professores disseram que não incentivariam, todos os outros licenciandos concordaram que seria interessante fazer uso dessa modalidade em sua prática profissional.

Após a apresentação dos aspectos teóricos, da definição, das vantagens e das opiniões pessoais, os futuros professores se reuniram em grupos. Foi distribuída uma folha impressa, com propostas que envolviam o uso das quatro operações, para que eles analisassem as possíveis estratégias utilizadas para efetuar o cálculo. Além disso, foram convidados a pensar nas propriedades matemáticas utilizadas caso efetuassem os cálculos mentalmente. Ao final, os futuros professores e as bolsistas compartilharam diferentes formas e perspectivas de se fazer uma mesma operação, possibilitando o surgimento de diferentes estratégias capazes de solucionarem uma operação simples de matemática.

A seguir, serão apresentadas algumas soluções compartilhadas durante a oficina. A Figura 2 apresenta duas resoluções diferentes para a operação: $98+269$. A primeira resolução utiliza a estratégia de completar em uma parcela e compensar em outra. A segunda resolução apresenta uma soma por partes, em que foi efetuado separadamente a soma das unidades e a soma das dezenas, para, no final, somar os dois resultados obtidos.

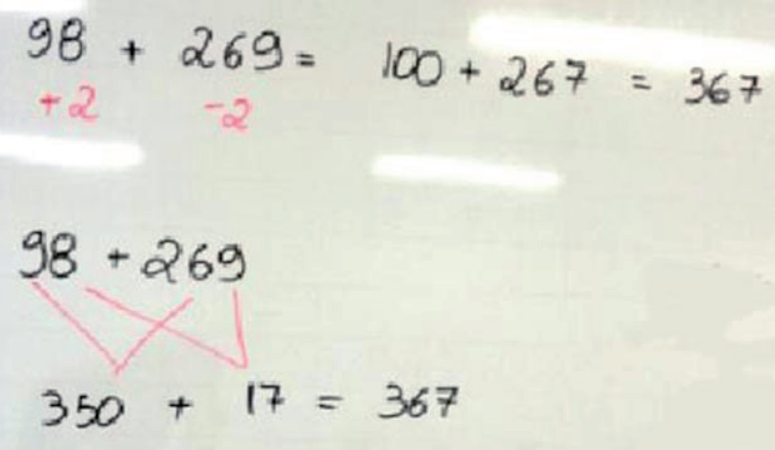

Figura 2: Diferentes maneiras de efetuar a soma proposta. Figure 2: Different ways to make the proposed sum. Fonte: Arquivo pessoal das autoras.

A Figura 3 exibe duas maneiras diferentes de resolver: 97-35. A primeira resolução apresenta a 
ideia por detrás do algoritmo da subtração, devido ao sistema de numeração ser decimal e posicional. Já a segunda resolução compartilha a estratégia de completar e compensar o minuendo e o subtraendo da operação.

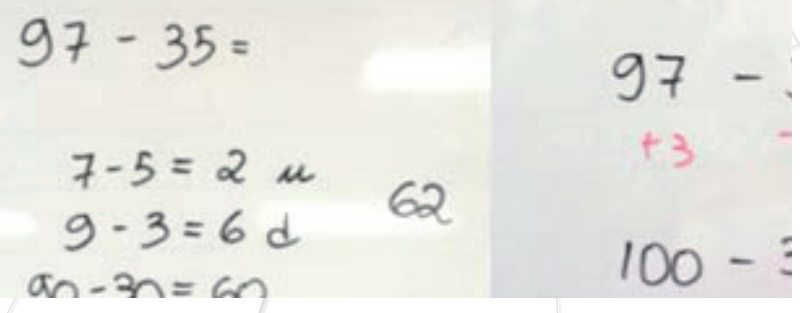

Figura 3: Diferentes maneiras de efetuar a subtração proposta.

Figure 3: Different ways to make the proposed subtraction.

Fonte: Arquivo pessoal das autoras.

A operação $16 \times 3$ foi proposta aos futuros professores e a Figura 4 exibe dois raciocínios distintos para efetuar a operação. O primeiro apresenta a decomposição dos fatores e a utilização da propriedade distributiva da multiplicação, tornando, dessa maneira, uma multiplicação mais complexa, em quatro multiplicações simples. A outra solução sugerida foi explorar a decomposição em fatores primos do número 16 , porque multiplicar mentalmente um número por dois quatro vezes pode ser mais simples do que multiplicá-lo apenas uma vez, neste caso por dezesseis.

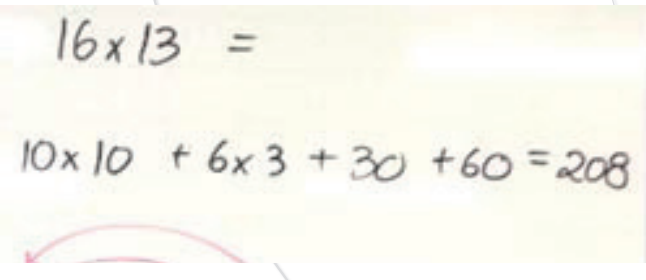

Figura 4: Diferentes maneiras de efetuar a multiplicação proposta.

Figure 4: Different ways to make the proposed multiplication. Fonte: Arquivo pessoal das autoras.

A imagem da Figura 5 exibe apenas uma maneira de efetuar a operação da divisão entre 125 por 25 e depois 1122 dividido por 11 . O princípio utilizado é a decomposição do dividendo e a "distributividade da divisão", isso porque dividir um número por "n" é o mesmo que o multiplicar pelo inverso de "n", logo pode ser utilizada a distributividade da multiplicação. O interessante de se utilizar essa estratégia é que, ao se efe-

tuar a operação $1122 \div 111122 \div 11$, é possível fugir do erro que alguns estudantes cometem ao efetuar o algoritmo, em que muitas vezes é dado como resposta 12 e não 102, como mostra a figura 5.

$$
\text { 16) } \begin{array}{ll}
125 \div 25 & 1122 \\
100 \div 25=4 \quad 25 \div 25=1 & \frac{11}{022} \\
(100+25) \div 25 & \frac{1122}{11}= \\
(100+25) \times \frac{1}{25} &
\end{array}
$$

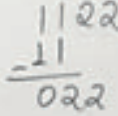

Figura 5: Diferentes maneiras de se efetuar a divisão proposta.

Fonte: Arquivo pessoal das autoras.

Alguns futuros professores apresentaram suas resoluções baseadas nos algoritmos, no entanto, solucionadas mentalmente. Ao discutir o modo como as operações foram resolvidas, percebe-se que algumas operações são mais fáceis de utilizar o algoritmo e pode-se atribuir a essa facilidade duas possibilidades: 1) A facilidade de efetuar o algoritmo mentalmente vem do fato de ele ser trabalhado em alguns momentos na sala de aula. 2) Como o algoritmo é baseado nas propriedades matemáticas do sistema de numeração decimal, a estratégia escolhida por alguns estudantes está fundamentada nessas propriedades.

Foi importante ressaltar aos futuros professores que o objetivo da oficina não era resolver as operações no quadro, mas as anotações foram necessárias para ilustrar os modos como elas foram solucionadas mentalmente. É importante salientar que o cálculo mental não exclui o uso simultâneo de outros instrumentos de cálculo, como o papel e o lápis, a calculadora, entre outros. Além disso, é permitida a anotação dos resultados intermediários. 


\section{OFICINA DE CALCULADORA}

A oficina de calculadora iniciou com o preenchimento de um questionário impresso, com seis questões que buscaram resgatar memórias, usos e concepções dos futuros professores sobre o uso desse instrumento. Nessa etapa, 17 futuros professores responderam ao questionário inicial. Após os questionários serem entregues, as respostas e as concepções dos licenciandos serviram de base para iniciarmos as discussões durante a oficina, que compreenderam teoria e prática.

Ao serem indagados: "Você se lembra quando foi a primeira vez que utilizou uma calculadora? Poderia descrever em qual situação isso ocorreu?" Constatamos que 14 futuros professores não se lembraram quando foi a primeira vez que utilizaram a calculadora e, entre as respostas encontramos: "não me lembro"; "não me recordo"; "não me lembro quando ocorreu"; "não me lembro da primeira vez"; "não lembro quando utilizei a calculadora pela primeira vez"; "não, acredito que já faz muito tempo". Entre os três futuros professores que se lembraram, dois deles indicaram a idade em que aprenderam a utilizar a calculadora. Um deles disse que aprendeu a usá-la com 11 anos e a conheceu após ver sua mãe fazendo uso dela ("Minha mãe tinha uma calculadora e, até então, eu não tinha visto e desconhecia as funcionalidades da calculadora. Nessa época, eu tinha 11 anos. Um certo dia, eu vi minha mãe utilizando e pedi para que ela me ensinasse"). Outra futura professora disse que aprendeu a usar a calculadora após ela ter chegado em sua casa ("quando era pequena, por volta dos 8 ou 9 anos. Meu irmão mais velho ganhou uma").

Quando as memórias se referem ao uso na escola, ao serem questionados: "Quais suas memórias a respeito do uso de calculadora na escola, quando você era estudante? Lembra o período aproximado ou série/ano?" Encontramos dois futuros professores que não se lembraram do uso na escola. Nove deles descreveram alguns detalhes sobre o uso, citando os Anos Finais do Ensino Fundamental e alguns conteúdos - cálculo de porcentagem, de áreas e de volumes e números decimais -, no entanto, alguns futuros professores citaram que o uso da calculadora só poderia acontecer, caso houvesse uma autorização da escola ("na escola utilizamos poucas vezes") e/ou do profes- sor ("em algumas aulas era permitido o uso da calculadora"; "o professor de matemática levou para a sala de aula uma atividade em que ficou permitido o uso da calculadora"; "a professora pouco nos deixava fazer o uso da calculadora em sala de aula").

Ainda nesse grupo, uma futura professora afirmou que, no Ensino Médio, eles eram autorizados a usar a calculadora durante as aulas, "mas na prova não podia". Seis futuros professores lembraram que não era permitido usar a calculadora na sala de aula e nas avaliações, chegando a comentar: "a minha turma levou calculadora para a prova do $1^{\circ}$ bimestre, só que o professor não autorizou o uso". A justificativa dos professores por não permitirem o uso da calculadora está relacionada ao fato de acreditarem que a calculadora atrapalha o raciocínio dos alunos ("os professores não gostavam muito, porque, segundo eles, o aluno deveria tentar usar o raciocínio e que a calculadora era para ser usada apenas em situações que necessitassem dela") e porque, nas avaliações que os alunos enfrentarão, eles não poderão utilizar tal instrumento ("nós não utilizamos calculadora nos anos finais, pois a escola estava preparando para o vestibular e ENEM e nessas provas não podia utilizar esse instrumento"). Em ambas as justificativas, os futuros professores relataram que, juntamente com seus colegas, as regras foram burladas ("Então, eu usava escondido do professor"; "vejo a turma usando debaixo da mesa, porque o professor não permitia, justificando que na prova do ENEM não teríamos esse recurso").

Nesse contexto, das memórias de uso não permitido pelos professores, indagamos se os futuros professores de matemática, utilizariam a calculadora com seus alunos: 14 deles informaram que a utilizariam, mas tiveram dificuldades de precisar o ano escolar, mas, em geral, apontando os Anos Finais do Ensino Fundamental e o Ensino Médio como as etapas adequadas. Dos três futuros professores que indicaram o não uso da calculadora em suas aulas, as justificativas foram: porque isso pode atrapalhar o raciocínio ("Quando ajudo algum aluno no meu estágio ou ajudo meu irmão com os deveres de casa, eu prefiro não utilizar para que ele possa tentar resolver as questões raciocinando, só uso em caso de grande necessidade"); por não ter usado no período escolar e por valorizar o cálculo mental e o cálculo escrito em detrimento da 
calculadora ("meus professores nunca me orientaram a fazer isso. E creio que foi muito mais útil o cálculo mental ou escrito"); e pela falta de oportunidades (“Porque não estou dando aula e no estágio não surgiu a oportunidade de trabalhar essa questão").

Em relação à segurança e à preparação na utilização da calculadora como recurso didático, obtivemos como resposta: sete futuros professores disseram que se sentem seguros e preparados e 10 deles não se sentem seguros. Entre os que se sentiam preparados, as justificativas, entre outras, foram: "pois é um recurso muito útil e prático" e "pois a calculadora é fácil de ser manuseada". Mas houve destaque também para o preparo do professor para desenvolver um bom trabalho: "Acredito que o uso da calculadora não deve ser feito de qualquer jeito, como com qualquer tecnologia em sala de aula, o professor precisa saber como utilizar e em quais momentos isso é oportuno".

Entre os que não se sentem preparados, encontramos como explicação o fato de não conhecerem todas as funcionalidade ("não tive contato com a calculadora na escola, não me ensinaram a manusear, então eu sei somente as operações básicas e eu sei que existem alguns recursos que poderiam ser muito úteis em muitos momentos, mas não sei usar"), o despreparo para trabalhar com o instrumento ("até hoje, não tive uma explicação de como se usa de forma didática a calculadora") ou ainda o fato de terem a concepção de que a calculadora poderia gerar dependência nos alunos ("Não, pois tenho receio de os alunos se tornarem dependentes, já que enquanto estudante não tinha a percepção de que a calculadora seria um recurso didático").

Após coletarmos e discutirmos sobre as concepções iniciais dos futuros professores sobre o uso da calculadora, apresentamos as potencialidades do uso desse instrumento, apoiadas nos referenciais teóricos de Imenes e Lellis (1997), Lopes e Rodriguez (2009) e, posteriormente, em atividades que exigiam o uso diferenciado da calculadora e da calculadora do celular (em comparação) (Figuras 6 e 7).

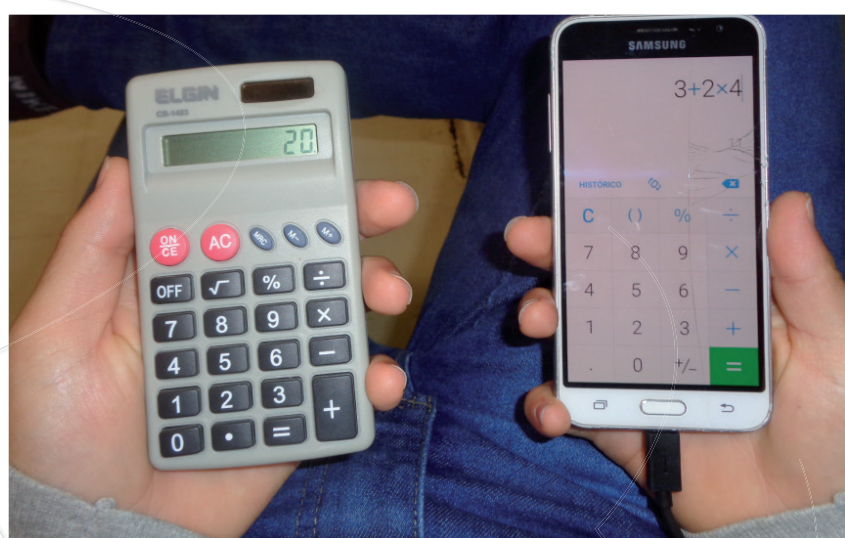

Figura 6: Estudante comparando as calculadoras (hierárquica e não hierárquica).

Figure 6: Student comparing calculators (hierarchical and non-hierarchical).

Fonte: Arquivo pessoal das autoras.

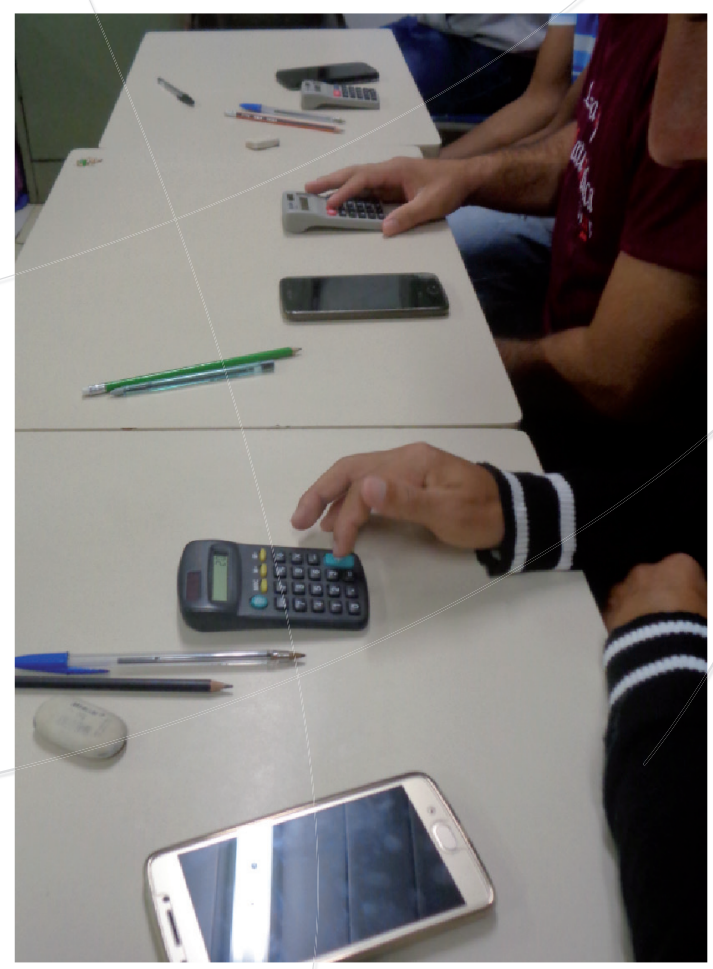

Figura 7: Propostas de atividades diferenciadas do uso da calculadora.

Figure 7: Differentiated Activity Proposals for Calculator Usage.

Fonte: Arquivo pessoal das autoras. 
Outras propostas de atividades apresentadas e exploradas pelos futuros professores foram os cálculos interativos, o uso das teclas de memória (Ex.: Memória aditiva: M+; Memória subtrativa: M-; Recuperar o acumulado na memória: RM, MR, MRC ou RCL, e etc.), além da análise de propostas apresentadas em livros didáticos. Outro recurso apresentado foi a "MusiCALcolorida" (FERNANDES et al., 2011), que pode auxiliar na introdução da calculadora e também no processo de inclusão de estudantes com deficiência visual e auditiva.

\section{CONSIDERAÇÕES SOBRE AS OFICINAS}

Sobre a oficina de cálculo mental, boa parte dos futuros professores respondeu que, após a oficina, se sentiram mais confiantes ao realizarem uma operação mentalmente, aumentando de $22 \%$ para $56 \%$ em relação ao questionário inicial que eles responderam antes de iniciarmos as atividades. Antes da oficina, $17 \%$ dos futuros professores se sentiam inseguros ao realizarem a operação mental, mas, após a realização da oficina, apenas $5 \%$ disseram que ainda se sentem inseguros ao praticarem essa modalidade de cálculos.

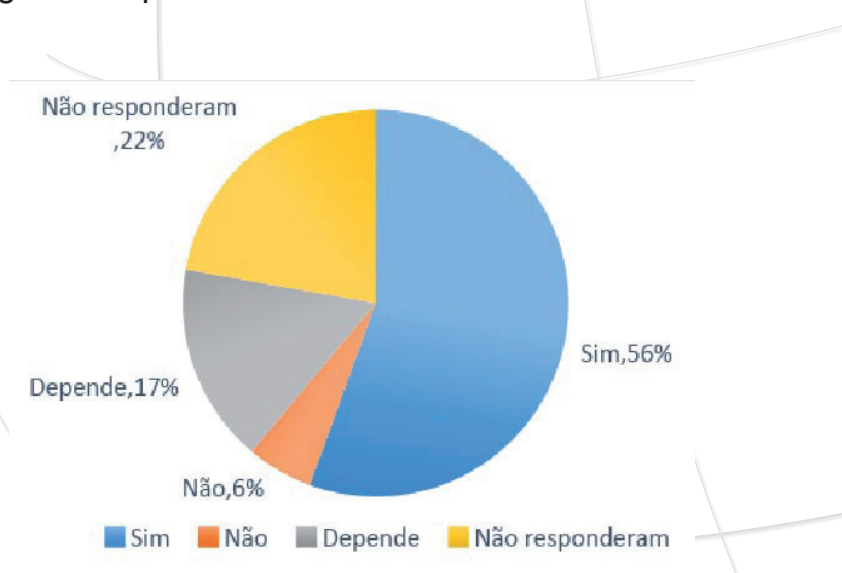

Gráfico 1: Manifestação de segurança ao realizar uma conta mentalmente após a oficina.

Graph 1: Demonstrating safety when performing a mental account after the workshop.

Fonte: Arquivo pessoal das autoras.

Todos os futuros professores, exceto um, disseram que "com certeza" incentivariam essa prática na sala de aula. Um futuro professor afirmou que o cálculo mental "possibilita que o aluno instigue seu lado epistemológico e busque maneiras mais rápidas e práticas de resolver um problema matemático sem depender das tecnologias".

Ao destacarem algum ponto interessante abordado, comentaram as contribuições e reflexões individuais que tiveram acerca do tema trabalhado na oficina, como: "A oficina me fez ver como é importante incentivar o cálculo mental e demonstrar as diversas formas de se resolver uma conta. Acho que isso pode colaborar para que o estudante descubra qual a melhor forma que ele consegue entender e resolver as operações"; "Através desta oficina percebi que existem várias maneiras de calcular uma simples conta de forma mental"; "Reforço no ensino e no aprendizado, e os conteúdos apresentados foram de grande importância para prepararmos os alunos a usarem e praticarem o cálculo mental"; "As contribuições foram inúmeras, já que nos proporcionou uma visão diferenciada do que era cálculo mental". Outro futuro professor respondeu:

A oficina contribuiu bastante para o meu entender sobre cálculo mental pois na minha trajetória escolar não me recordo de ter feito essa reflexão sobre o cálculo mental. Pude perceber que a partir do pensar é possível chegar ao mesmo resultado de quando utilizados os algoritmos $\mathrm{e}$ que, às vezes, estes cálculos podem facilitar para chegar no resultado final.

Sobre a oficina de calculadora, dos 18 participantes que realizaram o questionário final, ao serem indagados novamente sobre a segurança no uso da calculadora, por meio da questão "Você se sente seguro e preparado para usar a calculadora como um recurso didático?", 13 futuros professores escreveram que se sentem mais seguros e preparados, quatro sinalizaram que ainda não se sentem seguros e preparados e uma futura professora informou que ainda não se sente completamente segura e preparada. Nesse sentido, podemos comparar os dados, em relação ao mesmo questionamento proposto no início da oficina: 


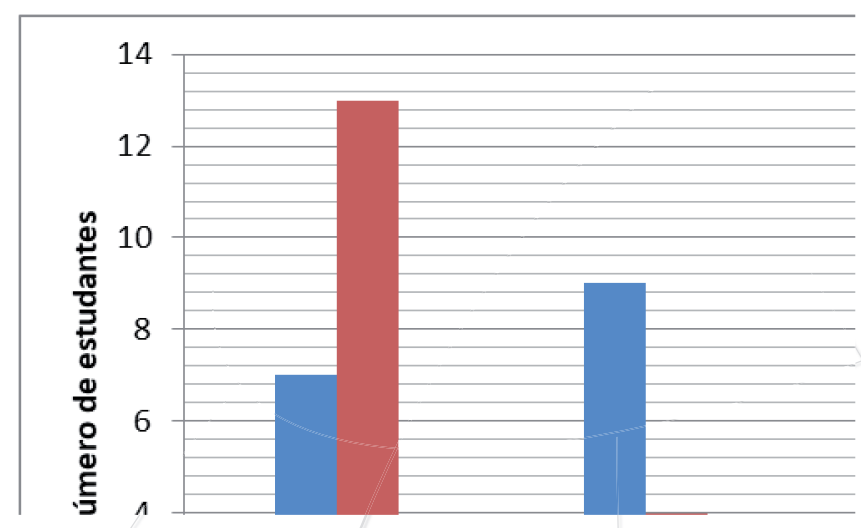

Gráfico 2: Você se sente seguro e preparado para usar a calculadora como recurso didático?

Graph 2: You feel safe and prepared to use the calculator as a didactic resource?

Fonte: Arquivo pessoal das autoras.

Felizmente, por meio das propostas de estudo e da prática na oficina de calculadora, os futuros professores declararam se sentirem mais preparados para usar a calculadora na sala de aula e, nesse sentido, acrescentaram: "Aprendi as funções de todas as teclas e também suas limitações. Além de ser um recurso acessível" e "com a oficina podemos ver as diversas possibilidades de usar a calculadora como recurso didático". Entre os que ainda não se sentem seguros, há justificativas que estão relacionados ao fato de quererem pesquisar mais, como por exemplo: "preciso pesquisar e fazer experimentações para preparar um bom plano de aula" ou "preciso explorar e praticar um pouco mais".

Os futuros professores ainda destacaram, num sentido avaliativo, a possibilidade de conhecerem os diversos tipos e as funções que a calculadora possui e de aprenderem a manuseá-la, além de citarem, também o cálculo mental (como na declaração de um deles: "perceber que ela pode ser utilizada como método didático sem prejudicar o cálculo mental”) e, de modo geral, a possibilidade de pensarem sobre o uso das tecnologias na sala de aula.

\section{CONSIDERAÇÕES FINAIS}

Este artigo teve como objetivo apresentar aspectos teóricos consideráveis sobre cálculo mental e calculadora, como as vantagens de desenvolver um trabalho com essas duas competências de cálculo na sala de aula. Visto isso, concluímos a importância de que sejam estimulados o uso do cálculo mental e da calculadora em toda a Educação Básica e não apenas em determinados anos do ensino básico. Isso poderia estar mais presente se os documentos curriculares brasileiros abordassem essas temáticas em todos os anos da Educação Básica e se houvesse uma formação para que os professores aprendam a trabalhar com essas modalidades na sala de aula.

Conscientes de que o principal responsável por estimular o uso, ou não, desses dois instrumentos em sala de aula é o professor, propusemos o estudo e a oficina junto aos estudantes do curso de Licenciatura em Educação do Campo - Habilitação Matemática. Essas oficinas objetivaram proporcionar reflexões e práticas sobre o cálculo mental e a calculadora, de maneira a estimular os participantes, futuros professores de Matemática, a promoverem um trabalho a partir dessas duas modalidades na Educação Básica.

Após a análise, acreditamos que as atividades, de maneira geral, obtiveram êxito em suas propostas, principalmente devido ao retorno positivo dado pelos estudantes. Consideramos que as oficinas atingiram todos os objetivos iniciais estabelecidos, que era discutir a importância dessas práticas com os futuros professores de Matemática, capacitá-los quanto à abordagem ou, pelo menos, despertar neles o interesse por essas modalidades de cálculos, incentivando essa prática na sala de aula. 


\section{REFERÊNCIAS}

ARAUJO, Denise; SOARES, Eduardo. Calculadoras e outras geringonças na escola. Presença Pedagógica, Belo Horizonte, v. 8 , n. 47, p. 22-35, set/ out. 2002.

AUAREK, Wagner Ahmad; VISEU, Floriano. Formação inicial do professor de matemática para escolas do Campo: novos 'olhares da comunidade campesina. Revista eletrônica de Educação Matemática. Florianópolis (SC), v. 12, n. 2, p. 247-261, 2017.

BOGDAN, R. C.; BIKLEN, S. K. Investigação qualitativa em educação: uma introdução à teoria dos métodos. (Coleção Ciências da Educação). Portugal: Porto Editora, 1994.

BOURDENET, Gilles. Le calcul mental. Activités mathématiques et scientifiques. Strasbourg: IREM, 2007. n. 61, p. 5-32.

BRASIL. Ministério da Educação e do Desporto. Secretaria de Educação Fundamental. Parâmetros Curriculares Nacionais: Matemática. Brasília: MEC/ SEF, 1997.

BRASIL. Ministério da Educação e do Desporto. Secretaria de Educação Fundamental. Parâmetros Curriculares Nacionais: matemática. Brasília, DF: MEC/SEF, 1998.

BRASIL. Ministério da Educação. Base Nacional Comum Curricular (BNCC). Educação é a base. Brasília: MEC/CONSED/UNDIME, 2018.

BROCARDO, Joana. Uma linha de desenvolvimento do cálculo mental: começando no $1^{\circ}$ ano e continuando até ao $12^{\circ}$ ano. In: Anais do PROFMAT2011 - ACTAS. Lisboa: Associação de Professores de Matemática - APM, 2011.

FERNANDES, Solange H. A. A. et al. Ver e ouvir a matemática com uma calculadora colorida e musical: estratégias para incluir aprendizes surdos e aprendizes cegos nas salas de aulas. In: PLETSCH, Marcia D.; DAMASCENO, Allan R. (Org.). Educação especial e inclusão escolar: reflexões sobre o fazer pedagógico. Seropédica/RJ: EDUR, 2011. p. 97-111.

FIORENTINI, Dario; LORENZATO, Sergio. Investigação em educação matemática: percursos teóricos e metodológicos. Campinas-SP: Autores Associados, 2006. (Coleção Formação de Professor).

GENTILE, Paola. Cálculo mental: contas de cabeça e sem errar. Nova Escola. São Paulo. 07 de março de 2018. Disponível em: <https://novaescola. org.br/conteudo/171/contas-de-cabeca-sem-errar-calculo-mental>. Acesso em: 21 maio 2018

GOMES, Maria Laura M. O cálculo mental na história da Matemática escolar brasileira. In: IX Enem - Encontro Nacional de Educação Matemática 2007. Disponível em: <http://sbem.iuri0094. hospedagemdesites.ws/anais/ix_enem/Html/comunicacaoCientifica.html>. Acesso em: 15 mar. 2018. GONÇALVES, Maria José S. V.; FREITAS, José Luiz M. O Cálculo mental como ferramenta e objeto durante 0 estudo de proporcionalidade por alunos do $7^{\circ}$ ano do ensino fundamental. In: XII EBRAPEM - Encontro Brasileiro de Estudantes de Pós-Graduação em Educação Matemática, 2008, Rio Claro, SP. Anais do XII EBRAPEM. Rio Claro,SP: UNESP, 2008. CD-ROM.

IMENES, Luiz Marcio P.; LELLIS, Marcelo. Matemática. São Paulo: Scipione, 1997.

LOPES, Antonio José; RODRIGUEZ, Joaquin G. Metodologia para o ensino da aritmética: competência numérica no cotidiano. São Paulo: FTD, 2009.

MOLINA, Monica Castagna. Expansão das licenciaturas em educação do campo: desafios e potencialidades. Educar em Revista. Curitiba, n. 55, p. 145-166, jan./mar. 2015.

PARRA, Cecilia. Cálculo mental na escola primária. In: PARRA, Cecilia; SAIZ, Irma. Didática da matemática: reflexões psicopedagógicas. Porto Alegre: Artes Médicas, 1996, p.186-235.

RIBEIRO, Raquel. Cálculo mental: quanto mais diversos os caminhos, melhor. Nova Escola. São Paulo. 01 de abril de 2005. Disponível em: <https://novaescola.org.br/conteudo/2686/calculo-mental-quanto -mais-diversos-os-caminhos-melhor>. Acesso em: 15 fev. 2018.

SELVA, Ana C. V.; BORBA, Rute E. S. R. O uso da calculadora nos anos iniciais do ensino fundamental. Belo Horizonte: Autêntica, 2010. (Coleção Tendências em Educação Matemática).

VAN DE WALLE, John. Matemática no ensino fundamental: formação de professores e aplicação em sala de aula. Tradução de Paulo Henrique Colonese. 6. ed. Porto Alegre: Artmed, 2009.

UNIVERSIDADE FEDERAL DE MINAS GERAIS. Projeto político pedagógico. Licenciatura em Educação do Campo. Belo Horizonte, 2009. 